\title{
Social communication deficits in disruptive primary-school children
}

\author{
R. Donno, G. Parker, J. Gilmour and D. H. Skuse
}

\section{Background}

Parent and teacher data, from questionnaire surveys, suggest that school-identified disruptive children often have pragmatic language deficits of an autistic type.

\section{Aims}

This replication study aimed to confirm earlier findings, using individual clinical assessment to investigate traits of autismspectrum disorder in disruptive children.

\author{
Method \\ Persistently disruptive children $(n=26)$ and a comparison \\ group $(n=22)$ were recruited from primary schools in \\ a deprived inner-city area. Measures included standardised \\ autism diagnostic interviews (with parents) and tests
}

of IQ, social cognition, theory of mind and attention (with children).

\section{Results}

The disruptive children possessed poorer pragmatic language skills $(P<0.0001)$ and mentalising abilities $(P<0.05)$ than comparisons. Nine disruptive children (35\%) met ICD-10 criteria for atypical autism or Asperger syndrome.

\section{Conclusions}

Many persistently disruptive children have undetected disorders of social communication, which are of potential aetiological significance.

\section{Declaration of interest}

None.
Persistently disruptive behaviour in primary-school children is associated with poorer mental and social adjustment in adulthood and lower educational attainment. ${ }^{1,2}$ Such behaviour is frequently observed in association with clinically diagnosed conduct disorder, hyperkinetic disorder and autism-spectrum disorders (disorders meeting ICD-10 criteria for childhood autism, Asperger syndrome or atypical autism). Children with conduct disorder display persistently antisocial, aggressive or defiant traits. Hyperkinetic disorder is characterised by early onset of overactive, poorly modulated behaviour with marked inattention. Autismspectrum disorder is defined in terms of deficits in social interaction and communication, with restricted interests and stereotyped patterns of behaviour. Diagnostic boundaries between these neurodevelopmental and behavioural disorders are not clear-cut and there is considerable comorbidity, ${ }^{3}$ suggesting the hypothesis that the conditions share certain neurocognitive deficits.

Moffitt et al proposed a shared neurodevelopmental basis for autism and early-onset persistent antisocial behaviour. ${ }^{4}$ Evidence in support of this hypothesis comes first from clinically identified samples of children with autism-spectrum disorder. Many also have conduct disorders, ${ }^{5}$ and are at high risk of exclusion from school. ${ }^{6}$ A complementary strand of evidence comes from clinical and community-identified samples of children with conduct disorder. Gilmour et al found, from their questionnaire-based survey, that school-identified persistently disruptive children often had pragmatic language skills deficits that were similar in quality and degree to those found in children with autism-spectrum disorder. ${ }^{1}$ They suggested that deficits in social communication can lead to behaviour that is antisocial and disruptive. Clinical experience and interviews with participating teachers revealed that a failure to understand social rules could lead to behaviour being interpreted, within the context of a school, as purposeful rulebreaking. ${ }^{6}$ Children who could speak in well-articulated sentences but lacked pragmatic language skills were sometimes labelled as defiant in the way they answered teachers' rhetorical questions (e.g. 'could you please all hold your tongues'). Their limited awareness of social hierarchy and theory of mind led to their pointing out teacher's mistakes in front of the class. Gilmour et al found that if such children lacked guilt or remorse following their wrongdoing, this could lead to an escalating confrontation. ${ }^{1}$ Children who had a low tolerance of routine changes in their dayto-day environment (such as the introduction of a new 'supply' teacher) could also react aggressively when resisting what they regarded as unreasonable demands.

The main aim of our replication study was to confirm the provisional conclusions of the original study, that many persistently disruptive children at primary school have undetected autistic behavioural traits. We selected a community sample of school-identified disruptive children, using similar criteria to those employed by Gilmour et al, ${ }^{1}$ with the objective of measuring the children's reciprocal social interaction, social communication, and repetitive and stereotyped behaviours, using individualised assessment. We employed a range of standardised diagnostic and neurocognitive measures that are sensitive to both autismspectrum disorder and attention-deficit hyperactivity disorder (ADHD) in light of the latter condition's association with conduct disorders. ${ }^{2}$ Neurocognitive skills assessed included attentional control/switching, ${ }^{7}$ facial emotion recognition, ${ }^{8}$ face recognition memory, ${ }^{9}$ judging directional eye gaze, ${ }^{10}$ and mentalising abilities. $^{11}$

\section{Method}

Ethical approval was sought from the local ethics committee and written consent was obtained from parents.

\section{Recruitment}

All 56 mainstream primary schools in the London borough of Hackney and the local pupil referral unit were invited to participate in the study. Hackney is an inner-city borough with a population of over 210000 and it is one of the most ethnically diverse and socially deprived in the UK. The borough suffers from 
low skill levels, high unemployment rates and low incomes. Many residents have poor literacy and numeracy skills, having left school with few qualifications. Means-tested and disability benefits support around $40 \%$ of families; most children are in families that are at least partially dependent on benefits. Sixteen primary schools $(29 \%$ of the total), with a combined population of 5091 children, volunteered to participate. Schools who declined reported that they were already engaged in other research projects or in statutory initiatives (e.g. Sure Start programmes) or were undergoing government inspection. All declined on the basis that they felt unable to commit to full participation. The schools that did participate were drawn from the full geographical breadth of the borough. The proportion of faith schools (5 of $16 ; 31 \%$ ) mirrors the national figure, which is about a third of all primary schools. ${ }^{12}$ Participating schools reflected the full range of performance level based on the most recent Office for Standards in Education (Ofsted) inspection: 2 were inadequate (12\%), 7 satisfactory (44\%), 4 good (25\%) and 3 excellent (19\%). The equivalent national figures for inner-city schools are $9 \%, 34 \%$, $38 \%$ and $20 \%$ respectively. ${ }^{13}$

Schools were asked to nominate all children who had a history of permanent or fixed-period exclusion, who were currently considered to be at high risk of exclusion, or 'whose behaviour had been of concern over time'. Our criteria aimed to ensure that nominated children were displaying a degree of disruptive behaviour that was of sufficient severity to impede access to learning. Our sample was therefore unbiased by differences between schools in the degree to which exclusion was employed as a method of managing disruptive behaviour. The research team visited each participating school. They explained the recruitment process, but did not reveal that the purpose of the investigation was to identify deficits in social communication disorders among disruptive pupils. The proportion of children deemed disruptive by each school differed little, implying that the schools had similar criteria for identifying such children.

Based on our initial discussions with them, schools requested a total of 290 packs to pass to families with disruptive children. Our potential sample reflected a $5.7 \%$ sample of the total pupil population on roll $(n=5091)$. This proportion mirrors government statistics on the proportions of children subject to permanent (4\%) and fixed-period (11.9\%) exclusions in Hackney in the year prior to the study. ${ }^{14}$ Schools also recruited comparison groups of children, matched for age and gender, from the same year group wherever possible. Information packs were passed to families. No details regarding children in either group were made available to researchers until consent was obtained from their parents.

Previous research, using the questionnaire-based Children's Communication Checklist, ${ }^{15}$ indicated an effect size of $d=1.7$ between typically developing children and those at risk of exclusion on measures of pragmatic language competence. ${ }^{1}$ A conservative estimate was adopted here $(d=0.9)$. Effect sizes for other measures of social cognition impairment were unknown. Power calculations indicated that with $\alpha=0.05$, a two-sided test, and $80 \%$ power to detect an effect as large as $d=0.9$, a total of 26 participants would be required in each group. ${ }^{16}$

\section{Participants}

A total of 26 persistently disruptive children were recruited, of whom 16 had a history of at least one fixed-period school exclusion and 10 were considered at high risk of exclusion. They were matched with 22 comparison children. The age range of the sample was 6-13 years. All children and parents were fluent in English, and all children were born in the UK. Children with a global intellectual disability, i.e. all those with IQ scores below 70 , were excluded from the study. To our knowledge no child in either group had previously been assessed by child psychiatry services, but this was not an exclusion criterion.

There was no significant difference between the groups in age, gender, ethnicity, social housing or verbal IQ (Table 1). The groups differed in performance IQ scores $(t=-3.32$, d.f. $=46$, $P=0.002$ ), with the comparison group performing at a higher level than the disruptive group. Parents of children in the disruptive group had fewer years of education than parents of comparison children $\left(\chi^{2}=16.62\right.$, d.f. $\left.=2, P<0.001\right)$.

\section{Measures}

\section{Children's Communication Checklist}

The Children's Communication Checklist (CCC) distinguishes between structural language impairment and impairment in the social use of language, and is used to assess pragmatic skills. ${ }^{15}$ It comprises 70 statements for which the rater checks whether each item definitely applies, applies somewhat or does not apply. These items contribute to the following subscales:
(a) intelligibility and fluency;
(b) syntax;
(c) inappropriate initiation;
(d) coherence;
(e) stereotyped conversation;
(f) use of context;
(g) rapport;
(h) social relationships;
(i) range of interests.

Subscales (c) to (g) combine to give a pragmatic composite score. Lower scores on the CCC are indicative of greater impairment. According to convention, significant clinical impairment is indicated by scores at least 2 standard deviations

\begin{tabular}{|c|c|c|c|}
\hline & $\begin{array}{l}\text { Disruptive group } \\
\qquad n=26\end{array}$ & $\begin{array}{l}\text { Comparison } \\
\text { group, } n=22\end{array}$ & $P^{a}$ \\
\hline $\begin{array}{l}\text { Age, years } \\
\text { Mean (s.d.) } \\
\text { Range }\end{array}$ & $\begin{array}{c}9.21(1.81) \\
6-13\end{array}$ & $\begin{array}{c}9.44(1.69) \\
6-12\end{array}$ & NS \\
\hline $\begin{array}{l}\text { Gender, } n(\%) \\
\quad \text { Male } \\
\text { Female }\end{array}$ & $\begin{array}{r}23(88) \\
3(12)\end{array}$ & $\begin{array}{r}18(82) \\
4(18)\end{array}$ & NS \\
\hline $\begin{array}{l}\text { Ethnicity, } n \text { (\%) } \\
\text { African-Caribbean } \\
\text { South Asian } \\
\text { White }\end{array}$ & $\begin{array}{c}15(58) \\
1(4) \\
10(38)\end{array}$ & $\begin{aligned} 10 & (45) \\
1 & (5) \\
11 & (50)\end{aligned}$ & NS \\
\hline $\begin{array}{l}\text { Parental education, } n(\%) \\
\text { Minimum compulsory level } \\
\text { Further education } \\
\text { Higher education }\end{array}$ & $\begin{aligned} 20 & (77) \\
4 & (15) \\
2 & (8)\end{aligned}$ & $\begin{array}{r}4(18) \\
10(46) \\
8(36)\end{array}$ & $<0.001$ \\
\hline Social housing, $n$ (\%) & $21(81)$ & $17(77)$ & NS \\
\hline $\begin{array}{l}\text { Verbal IQ score } \\
\text { Mean (s.d.) } \\
\text { Range }\end{array}$ & $\begin{array}{c}98.19(16.42) \\
65-142\end{array}$ & $\begin{array}{c}105.73(16.21) \\
78-134\end{array}$ & NS \\
\hline $\begin{array}{l}\text { Performance IQ score } \\
\text { Mean (s.d.) } \\
\text { Range }\end{array}$ & $\begin{array}{c}90.23(13.88) \\
72-136\end{array}$ & $\begin{array}{c}104.68(16.31) \\
78-138\end{array}$ & $<0.01$ \\
\hline
\end{tabular}


below the population mean. ${ }^{3}$ We adopted a more stringent cut-off of 3 standard deviations, as this application of the CCC was in a novel non-clinical population, and we wanted to avoid false-positive identification. The CCC was used in the original study by Gilmour et $a l^{1}$ and was completed by both parents and teachers. We aimed to use this measure to confirm the sample of children recruited here was comparable with the original study sample in terms of social communication deficits.

\section{Developmental, Dimensional and Diagnostic Interview}

The Developmental, Dimensional and Diagnostic Interview (3DI) is a computerised structured clinical interview, administered by trained clinicians to parents or caregivers of children with suspected autism. ${ }^{17}$ It is designed to assess autistic behaviours and childhood psychiatric symptoms dimensionally, using parent and teacher report (the latter contributing to diagnostic algorithms for ADHD and conduct disorder). Output is designed to emulate the diagnostic algorithm of the Autism Diagnostic Interview - Revised (ADI-R). ${ }^{18}$ Dimensions include reciprocal social interaction skills; social expressiveness; use of language and other communication skills; use of gesture and non-verbal play; and repetitive or stereotyped behaviours and routines. The 3DI comprises 183 questions relating to demography and developmental history and 266 questions concerned with disorders on the autism spectrum. A further 291 questions relate to other psychiatric diagnoses, but only those pertaining to hyperkinetic disorder (ADHD) and conduct disorders were asked. Information from the 3DI enables classification according to ICD-10 and DSM-IV-TR research criteria for childhood autism, Asperger syndrome, atypical autism (ICD-10), pervasive developmental disorder not otherwise specified (DSM-IV-TR) and pragmatic language disorder. ${ }^{19,20}$ Diagnostic categories are defined so as to be mutually exclusive. The 3DI shows excellent test-retest and interrater reliabilities, with most intraclass correlation coefficients (ICC) greater than 0.9. ${ }^{17}$ Concurrent validity assessed by agreement with independent clinician diagnosis is very good (Cohen's $\kappa=0.74$ ). Criterion validity compared with the ADI-R is excellent for clinical cut-off points of the main subscales: reciprocal social interaction $86 \%$, communication $100 \%$, repetitive and stereotyped behaviours $76 \%{ }^{17}$ Raters were trained in the administration of the 3DI and subsequently achieved the requisite standard of interrater reliability.

\section{Intellectual ability}

The Wechsler Abbreviated Scales of Intelligence (WASI) provided measures of verbal IQ and non-verbal ability (performance IQ). ${ }^{21}$

\section{Attention and executive function}

The Test of Everyday Attention for Children (TEA-Ch) was used to measure selective and sustained attention plus attentional control/ switching. ${ }^{22}$ It has good test-retest reliability $(r=0.57-0.87)$ and excellent construct validity, and shows high correlations with established measures of attention and executive functioning. ${ }^{22}$

\section{Social cognition}

Social cognition was assessed with the Schedules for the Assessment of Social Intelligence (SASI), ${ }^{23}$ a set of computerised measures of social cognition that are sensitive to deficits shown by individuals with autism-spectrum disorder. ${ }^{10}$ All tasks have excellent test-retest reliability and they discriminate well between children with autism-spectrum disorder and typically developing children. ${ }^{23}$ Individual accuracy scores were obtained for the following tasks.

Emotion recognition. Sixty facial images of emotional expressions are presented to the child, ten each of fear, anger, disgust, sadness, happiness and surprise. ${ }^{24}$ The six emotion terms are presented at the side of each face. Children are asked to match the expression to the appropriate emotion term.

Gaze monitoring. Gaze monitoring measures accuracy in detection of eye gaze from a static photograph, with eyes deviated between 5 and 20 degrees from the midline. Children are presented with 30 faces and asked to indicate whether the person is looking to the left, the right or into their eyes.

Face recognition memory. The Recognition Memory Test Faces presents 50 black-and-white photographs of men in a structured timed format. ${ }^{25}$ These 50 pictures are then presented again in a random order paired with a distracter (a male face that has not been seen before). Children are asked to indicate which of the pair of faces they have already seen.

\section{Theory of mind}

The Theory of Mind task involves attributing mental states to animated shapes. ${ }^{26,27}$ Eight silent cartoons are shown on a computer screen, each lasting approximately $40 \mathrm{~s}$. Each cartoon features a large red triangle and a smaller blue triangle moving around a framed white background. There are two conditions, with four animations in each condition. The experimental condition consists of theory of mind animations in which the movements of one object are decoupled from those of the other, generating a reactive pattern. The cartoon activities are surprising, mocking, coaxing and seducing. These types of action patterns are intended to elicit mental state (theory of mind) descriptions. The control condition consists of goal-directed animations, in which the actions of one object show a simple dependency on those of the other; these cartoons involve the joint activities of dancing, fighting, chasing and leading. In earlier studies, these cartoons were shown to be unlikely to evoke descriptions that included mental states. Although action contingencies differ between the cartoon types, their visual characteristics in terms of shape and number of agents, general dynamic characteristics and orientation changes are similar. The children's verbal responses to each animation were recorded, and subsequently scored in terms of their intentionality and appropriateness. The intentionality score reflects the degree of intentional attribution to the relative movements of the shapes, and the appropriateness score reflects the degree to which the events in the cartoons are understood, i.e. the accuracy of the response. Intentionality scores range from 0 to 5 , with absence of intentional language at one extreme and elaborate use, incorporating mental states, at the other. Appropriateness scores range from 0 to 2 , with a score of 0 for no response or a totally inappropriate response, 1 for a partly appropriate response and 2 for a fully appropriate response. Interrater reliability was good for ratings made of responses that captured both intentionality $(\mathrm{ICC}=0.90)$ and appropriateness $(\mathrm{ICC}=0.73)$. When the raters disagreed the more conservative rating was used.

\section{Procedure}

Prior to the individual assessment, families and teachers completed questionnaires, including the CCC. Families were 


\begin{tabular}{|c|c|c|c|c|c|c|}
\hline \multirow[b]{2}{*}{ Scale } & \multicolumn{2}{|c|}{ Parent data } & \multirow[b]{2}{*}{$P$} & \multicolumn{2}{|c|}{ Teacher data } & \multirow[b]{2}{*}{$P$} \\
\hline & $\begin{array}{l}\text { Disruptive group } \\
\qquad n=26\end{array}$ & $\begin{array}{c}\text { Comparison group } \\
n=2\end{array}$ & & $\begin{array}{l}\text { Disruptive group } \\
\qquad n=25\end{array}$ & $\begin{array}{l}\text { Comparison group } \\
\qquad n=21\end{array}$ & \\
\hline \multicolumn{7}{|l|}{ Intelligibility and fluency } \\
\hline Mean (s.d.) & $33.38(4.73)$ & $34.73(1.75)$ & NS & $33.32(4.39)$ & $34.24(1.87)$ & NS \\
\hline Range & $18-38$ & $31-38$ & & $18-38$ & $30-37$ & \\
\hline Clinical range, $n(\%)$ & $6(23)$ & $0(0)$ & NS & $4(16)$ & $1(5)$ & NS \\
\hline \multicolumn{7}{|l|}{ Syntax } \\
\hline Mean (s.d.) & $30.58(1.58)$ & $31.45(0.86)$ & NS & $30.76(1.62)$ & $31.67(0.66)$ & NS \\
\hline Range & $26-33$ & $30-32$ & & $26-32$ & $30-32$ & \\
\hline Clinical range, $n(\%)$ & $5(19)$ & $0(0)$ & NS & $4(16)$ & $0(0)$ & NS \\
\hline \multicolumn{7}{|c|}{ Pragmatic composite score } \\
\hline Mean (s.d.) & $134.69(10.26)$ & $153.86(7.13)$ & 0.001 & $142.20(11.84)$ & $152.95(7.28)$ & 0.03 \\
\hline Range & $113-154$ & $135-162$ & & $118-161$ & $133-160$ & \\
\hline Clinical range, $n(\%)$ & $11(42)$ & $0(0)$ & $<0.0001$ & $5(20)$ & $0(0)$ & 0.001 \\
\hline
\end{tabular}

assessed in their own homes, with parents and children seen concurrently in separate rooms.

\section{Results}

The disruptive and comparison groups were well balanced for age, gender, verbal IQ, ethnicity and most indicators of socioeconomic status, but there were significant differences in performance IQ and parental education. Significant results are therefore only reported when effects remained after these potentially confounding variables were controlled for in the analysis.

\section{Children's Communication Checklist}

Table 2 shows the mean scores and percentage in the clinical range for the CCC structural language subscales and pragmatic composite scores from parent and teacher ratings. To avoid inflating type 1 error due to multiple comparisons on this measure, we applied Bonferroni adjustments to significance levels. Parent and teacher CCC total pragmatic composite scores were moderately correlated $(r=0.45, n=46, P=0.002)$. The subscales that contribute to the pragmatic composite scale score include inappropriate initiation, coherence, stereotyped language, use of context and rapport. These data substantially support our hypotheses. Significantly more disruptive than comparison children obtained scores in the clinical range on the pragmatic composite scale (parent data: $\chi^{2}=12.08$, d.f. $=1, \quad n=48$, $P=0.001$; teacher data: $\chi^{2}=4.71$, d.f. $=1, n=46, P=0.03$ ). Comparing the mean scores within each subscale for the teacher-rated CCC scores obtained at the time of our initial study, ${ }^{1}$ for both disruptive and comparison children, we found no significant difference with respect to the latter group. The initial sample of children with conduct disorder obtained significantly lower scores than the current sample of disruptive children with respect to all subscales contributing to the pragmatic composite score (approximately 1.0 standard deviation in each case).

\section{Developmental, Dimensional and Diagnostic Interview}

Table 3 shows the mean scores on the main subscales and the proportions in the clinical range of the 3DI autism-spectrum disorder dimensions for both groups. Cut-off scores for the clinical range are indicated in the table. There were significantly more children in the disruptive group than in the comparison group in the clinical range for reciprocal social interaction $\left(\chi^{2}=9.37, \quad\right.$ d.f. $\left.=1, \quad n=48, \quad P=0.002\right), \quad$ social expressiveness $\left(\chi^{2}=11.84\right.$, d.f. $\left.=1, n=48, P=0.001\right)$ and language and other social communication skills $\left(\chi^{2}=15.15, \quad\right.$ d.f. $=1, \quad n=48$, $P<0.0001)$. There was no significant group difference for gesture and non-verbal play $\left(\chi^{2}=0.76\right.$, d.f. $\left.=1, n=48\right)$ but this was not unexpected, as this scale is not discriminating among children with IQ scores in the normal range. There were, however, similar group scores in terms of restricted, repetitive and stereotyped behaviours and activities ( $\chi^{2}=1.77$, d.f. $=1, n=48$, not significant).

\section{Diagnoses}

Table 3 shows the number of children diagnosed on the basis of ICD-10 Research Diagnostic Criteria with autism-spectrum,

Table 3 Developmental, Dimensional and Diagnostic

Interview scores

Disruptive group Comparison

$n=26 \quad$ group, $n=22 \quad P$

Dimensions

Reciprocal social interaction

Mean (s.d.)

Range

Clinical range, $n(\%)$

Social expressiveness

Mean (s.d.)

Range

Clinical range, $n(\%)$

Language

Mean (s.d.)

Range

Clinical range, $n$ (\%)

Gesture and non-verbal play

Mean (s.d.)

Range

Clinical range, $n$ (\%)

Repetitive and stereotyped

behaviour

Mean (s.d.)

Range

Clinical range, $n(\%)$

$\begin{array}{cc}8.64(2.89) & 4.22(1.52) \\ 3.90-13.80 & 1.90-7.30 \\ 9(35) & 0(0) \\ & \\ 1.43(0.58) & 0.83(0.43) \\ 0.00-2.40 & 0.00-1.80 \\ 22(85) & 8(36)\end{array}$

0.002

$-7.30$

$83(0.43)$

0.001

$8.92(3.87) \quad 4.36(1.75)$

3.00-18.10 1.90-8.20

15 (58) $\quad 1$ (5)

$4.15(2.69) \quad 2.32(1.75)$

0.50-10.20 $\quad 0.30-7.10$

$3(12) \quad 1(5)$

Diagnoses, $n(\%)$

Asperger syndrome

Atypical autism

Total ASD

Conduct disorders

Hyperkinetic disorder

$\begin{array}{cc}0.85(1.14) & 0.31(0.55) \\ 0.00-4.00 & 0.00-1.80 \\ 2(8) & 0(0)\end{array}$

NS

$\begin{array}{ccc}2(8) & 0(0) & \text { NS } \\ 7(28) & 0(0) & 0.008 \\ 9(35) & 0(0) & 0.002 \\ 18(72) & 0(0) & <0.0001 \\ 2(8) & 0(0) & N S \\ \text { significant. } & & \end{array}$

ASD, autism-spectrum disorder; NS, not significant. 
conduct and hyperkinetic disorders. Nine children $(35 \%)$ in the disruptive group met criteria for an autism-spectrum disorder, but none in the comparison group did so $\left(\chi^{2}=9.37\right.$, d.f. $=1$, $n=48, P=0.002)$. Eighteen children in the disruptive group met ICD-10 criteria for conduct disorder; this was not the case for any child in the comparison group $\left(\chi^{2}=24.37\right.$, d.f. $=1, n=48$, $P<0.0001)$. There was no significant between-group difference in the number of children meeting criteria for hyperkinetic disorder $\left(\chi^{2}=1.76\right.$, d.f. $\left.=1, n=46\right)$.

\section{Attention/executive functioning}

Means and standard deviations for TEA-Ch factor scores are shown in Table 4. Factor scores were derived as described in the

\begin{tabular}{|c|c|c|c|}
\hline & $\begin{array}{l}\text { Disruptive } \\
\text { group }^{a}\end{array}$ & $\begin{array}{l}\text { Comparison } \\
\text { group }^{a}\end{array}$ & $P$ \\
\hline \multicolumn{4}{|c|}{ TEA-Ch factor scores } \\
\hline \multicolumn{4}{|c|}{ Selective attention } \\
\hline Mean (s.d.) & $16.13(6.00)$ & $16.73(5.20)$ & NS \\
\hline Range & $8-28$ & $9-25$ & \\
\hline$n$ & 24 & 22 & \\
\hline \multicolumn{4}{|c|}{ Sustained attention } \\
\hline Mean (s.d.) & $38.20(13.47)$ & $45.62(11.71)$ & NS \\
\hline Range & $15-64$ & $23-64$ & \\
\hline$n$ & 20 & 21 & \\
\hline \multicolumn{4}{|c|}{ Attentional control/switching } \\
\hline Mean (s.d.) & $16.21(6.51)$ & $18.83(5.73)$ & NS \\
\hline Range & $2-26$ & $6-27$ & \\
\hline$n$ & 14 & 18 & \\
\hline \multicolumn{4}{|l|}{ Social cognition } \\
\hline \multicolumn{4}{|c|}{ Gaze monitoring task } \\
\hline Mean (s.d.) & $45.90(8.45)$ & $52.82(9.66)$ & NS \\
\hline Range & $33-63$ & $33-67$ & \\
\hline$n$ & 26 & 22 & \\
\hline \multicolumn{4}{|c|}{$\begin{array}{l}\text { Appropriate mentalising } \\
\text { responses }\end{array}$} \\
\hline Mean (s.d.) & $1.27(1.19)$ & $2.18(1.71)$ & 0.035 \\
\hline Range & $0-4$ & $0-6$ & \\
\hline$n$ & 26 & 22 & \\
\hline $\begin{array}{l}\text { NS, not significan } \\
\text { a. Missing data in } \\
\text { assessment. }\end{array}$ & $\begin{array}{l}\text { ryday Attention } \\
\text { to withdrawal o }\end{array}$ & $\begin{array}{l}\text { Children. } \\
\text { sent from childre }\end{array}$ & uring \\
\hline
\end{tabular}

TEA-Ch manual. ${ }^{22}$ No significant between-group difference was found on any factor (selective attention $t=-0.36$, d.f. $=44$, $n=46$; sustained attention $t=-1.88$, d.f. $=39, n=41$; attentional control/switching $t=-1.21$, d.f. $=30, n=32$ ).

\section{Social cognition}

No significant between-group difference was observed for accuracy scores on the facial emotion recognition task (happy $t=-1.64$, d.f. $=46, n=48$; surprise $t=0.00$, d.f. $=46, n=48$; fear $t=-0.65$, d.f. $=46, n=48$; sad $t=-1.29$, d.f. $=46, n=48$; disgust $t=-0.13$, d.f. $=46, n=48$; anger $t=-1.12$, d.f. $=46, n=48)$ or on the face recognition memory task $(t=-1.11$, d.f. $=45, n=47)$. However, we did find small but significant group differences on the gaze monitoring task. Following the approach of Baron-Cohen et $a l,{ }^{28}$ we calculated the highest score that could reasonably be obtained by chance. This score reflects the upper bound of the $95 \%$ confidence interval around chance scores. The use of 30 trials with three response options $\left(P_{\text {correct }}=0.3\right)$ means that scores in excess of 13 ( $43 \%$ correct) are unlikely to occur simply by chance. One-sample $t$-tests showed scores were significantly better than chance in the comparison group $(t=4.77$, d.f. $=21, n=22$, $P<0.0001$ ), whereas the scores of children in the disruptive group were not significantly different from chance $(t=1.75$, d.f. $=25$, $n=26)$. Thirteen of the disruptive group performed at or below chance level, compared with just four in the comparison group $\left(\chi^{2}=5.27\right.$, d.f. $\left.=1, n=48, P=0.02\right)$.

\section{Theory of mind}

Children in the disruptive group gave fewer appropriate mentalising responses than comparisons, defined as responses receiving a rating of 1 or 2 on appropriateness and 4 or 5 on intentionality (disruptive group mean 1.27 , s.d. $=1.19$, comparison group mean 2.18, s.d. $=1.71 ; t=-2.18$, d.f. $=44, n=46, P=0.035$ ).

\section{Autism-spectrum disorder subgroup}

The subgroup of nine disruptive children who were comorbid for both conduct disorder and Asperger syndrome or atypical autism is insufficiently large for most statistical analyses based on withingroup or between-group comparisons. Nevertheless, we were concerned to characterise the neurocognitive profile of these

\begin{tabular}{|c|c|c|c|c|c|c|c|}
\hline & ICD-10 diagnosis & $\begin{array}{l}\text { Age, } \\
\text { months }\end{array}$ & Gender & $\begin{array}{l}\text { VIQ } \\
\text { score }\end{array}$ & $\begin{array}{l}\text { PIQ } \\
\text { score }\end{array}$ & $\begin{array}{c}\text { Appropriate } \\
\text { mentalising response }\end{array}$ & $\begin{array}{l}\text { Pragmatic composite } \\
\text { score (parent data) }\end{array}$ \\
\hline Case 1 & Atypical autism & 123 & Male & 87 & 99 & 1 & 125 \\
\hline Case 9 & Atypical autism & 104 & Male & 107 & 88 & 1 & 138 \\
\hline Case 10 & Atypical autism & 160 & Male & 80 & 83 & 1 & 131 \\
\hline Case 11 & Atypical autism & 116 & Female & 99 & 93 & 2 & 137 \\
\hline Case 12 & Asperger syndrome & 88 & Male & 106 & 97 & 0 & 119 \\
\hline Case 16 & Atypical autism & 142 & Male & 109 & 107 & 2 & 130 \\
\hline Case 18 & Asperger syndrome & 126 & Male & 142 & 136 & 2 & 120 \\
\hline Case 19 & Atypical autism & 124 & Male & 100 & 72 & 3 & 151 \\
\hline Case 22 & Atypical autism & 131 & Male & 125 & 109 & 0 & 113 \\
\hline \multicolumn{8}{|c|}{ Subgroup descriptive statistics $(n=9)$} \\
\hline \multicolumn{2}{|c|}{ Mean (s.d.) } & $123.78(20.71)$ & & $106.11(18.67)$ & $98.22(18.28)$ & $1.33(1.00)$ & $129.33(11.65)$ \\
\hline \multicolumn{2}{|c|}{ Range } & $88-160$ & & 80-142 & $72-136$ & $0-3$ & 113-151 \\
\hline \multicolumn{8}{|c|}{ Comparison group descriptive statistics $(n=22)$} \\
\hline \multirow{2}{*}{\multicolumn{2}{|c|}{$\begin{array}{l}\text { Mean (s.d.) } \\
\text { Range }\end{array}$}} & $113.23(20.23)$ & & $105.73(16.21)$ & $104.68(16.31)$ & $2.18(1.71)$ & $153.86(7.13)$ \\
\hline & & $79-148$ & & $78-134$ & $78-138$ & $0-6$ & 135-162 \\
\hline \multicolumn{4}{|c|}{ Subgroup $v$. comparison group effect sizes $(d)$} & & & 0.61 & 2.53 \\
\hline
\end{tabular}


children on tests that had shown significant between-group differences in the full sample (Table 5). This subgroup had exceptionally poor pragmatic language abilities. Group difference on the pragmatic composite scale of the CCC was substantial $(d=2.53)$, indicating that the average child in the comparison group performed above the 97.7th percentile of the autismspectrum disorder subgroup. ${ }^{16}$ The mean pragmatic composite score of the autism-spectrum disorder subgroup fell more than 3 standard deviations below the mean of the comparison group. Children in this subgroup also had very poor mentalising abilities as measured by the animations task. Two children gave no appropriate mentalising response, and the magnitude of group difference was moderate $(d=0.61)$.

\section{Discussion}

This study replicates previous findings indicating that a relatively high proportion of children with severe and persistent disruptive behaviour have social communication impairments. ${ }^{1}$ Whereas the previous survey (in the same inner-city borough) was based on questionnaire reports, we used a more comprehensive assessment, employing parental interviews and direct neurocognitive testing of children. Nearly half ( $42 \%$ ) of children designated by their schools as being persistently disruptive obtained pragmatic language scores (parent-rated) that were at least 3 standard deviations below population norms, consistent with clinically significant levels of impairment. On the basis of our standardised diagnostic interview, 9 of $26(35 \%)$ disruptive children met clinical criteria for an autism-spectrum disorder. Children who were persistently disruptive performed more poorly than comparisons on neurocognitive tests of their ability to recognise direction of eye gaze and demonstrate appropriate mentalising skills (theory of mind). ${ }^{10}$

A significant minority of disruptive children met criteria for both conduct disorder and autism-spectrum disorder, yet so far as we could ascertain none had ever been seen by psychiatric services. We considered the possibility that our findings of social communication impairment reflected comorbidity between ADHD and autism-spectrum disorder. ${ }^{5,29}$ Surprisingly, we found no group difference in the proportions in the case and comparison groups with $\mathrm{ADHD}$, and no evidence for a significantly greater prevalence of attention problems in the case sample on the basis of standardised neurocognitive testing. We consider it likely that social communication difficulties had a causal role in the development of disruptive behaviour, on the basis of detailed information from the family interviews about the temporal progression of the child's problems. Our evidence suggests that many children of primary-school age with conduct disorder have social communication deficits severe enough to warrant a diagnosis of autism-spectrum disorder, and that those deficits are often overlooked. The ICD-10 recognises that conduct disorders can be symptomatic of other disorders, and children with autism-spectrum disorder (especially those with normalrange IQ scores) have previously been misidentified in community samples. ${ }^{30}$

We cannot be certain that the social communication deficits we identified have a neurodevelopmental origin, or that their origin is the same as social communication deficits in cases of autism-spectrum disorder that are not associated with persistently disruptive behaviour. Whatever the aetiology of their social communication difficulties, within the school environment the children we identified as having these traits acted in ways that brought them into conflict with teachers and peers. Furthermore, the reasons for their exclusion were similar to those for exclusions of children with clinically diagnosed autism. ${ }^{6}$
The main domains of social communicative impairment we identified were in terms of reciprocal social interaction skills plus verbal and non-verbal communication. Few children in the disruptive group had significant problems in the domain of repetitive or stereotyped behaviours, although by definition those behaviours were present in the two children meeting clinical criteria for Asperger syndrome. Subclinical levels of stereotyped or repetitive behaviours were reported in all but one child who met criteria for atypical autism. Fewer stereotyped and repetitive behaviours have consistently been found in children who are diagnosed with atypical autism compared with those with autism or Asperger syndrome. ${ }^{31}$ Elsewhere we have argued that the importance of a relationship between social communication impairments and stereotypy has been exaggerated in our current conceptualisation of autism-spectrum disorder, and suggested that these domains may have largely independent underlying biological causes. $^{32}$

Children in the disruptive group were not significantly worse at identifying facial expressions of emotion nor were they worse at a face recognition memory task than comparisons. A significant proportion of individuals with autism-spectrum disorder experience difficulty on these tasks. ${ }^{9,10}$ However, previous studies have also suggested that the cognitive endophenotypes associated with social communication abilities may be more fractionated in high-functioning children with autism-spectrum disorder compared with their peers, ${ }^{33}$ such that children may show difficulties on some tasks but not on others.

\section{Limitations of the study}

There is clearly a need for replication of the findings of this study. We acknowledge that we cannot be sure of its representativeness, on the grounds that we recruited a relatively small sample and our focus was on one socioeconomically disadvantaged inner-London borough. The generalisation of our findings to other populations hangs on the representativeness of our sample of persistently disruptive children. Relevant to the issue of potential bias in the selection of our sample are the following issues. First, were the schools that agreed to participate in our study representative of all primary schools in the borough? We have no reason to think that a systematic bias operated here: on all measures we have identified, the schools appeared to be a random sample, perhaps rather less likely to be involved in research than those that were already participating in other studies and were therefore unavailable. Second, were the children nominated by the schools as being persistently disruptive representative of all disruptive children? So far as we can tell the proportions nominated were in line with previous data on the proportions at risk of exclusion, and there was little between-school variation. Third, were the families who agreed to participate in our research representative of all families with severely disruptive pupils? Although the response rate among our sample was low, this is to be expected when working with any hard-to-reach population, without providing incentives for participation. We have no evidence that the proportion agreeing to take part were more likely to have participated because they had concerns about their child's social communication skills. We did not indicate either to families or to schools that we were seeking to identify children with suspected autism-spectrum disorders. Fourth, were the children in our comparison sample especially well adjusted, or superior to the general population in any way relevant to the hypotheses being tested in this study? There is no evidence that the comparison group had superior functioning compared with the general population on any norm-referenced measures used. The mean scale 
scores on the CCC for teacher ratings of comparison children were almost identical to those obtained in our initial investigation. ${ }^{1}$

Hackney is one of the most socioeconomically deprived boroughs in the UK. Low socioeconomic status has consistently been associated with persistent disruptive behaviour, ${ }^{34}$ and the reasons why these schools had children with such problems may have differed from schools in other sociodemographic regions. Case and comparison groups were well balanced for family socioeconomic status, and between-group differences in parental education were statistically controlled throughout the analysis. Furthermore, it has been repeatedly demonstrated that mentalising skills, ${ }^{34}$ and also pragmatic language skills (D. Bishop, personal communication, 2006), are independent of socioeconomic status. We controlled for IQ differences between groups in both our design and analyses. The pattern of intra-individual verbal and non-verbal IQ scores we observed (verbal IQ tending to be greater than performance IQ) is opposite to that found in children without autism with severe emotional and behavioural disorders. ${ }^{35}$ Finally, we found no greater impairment in attention or executive functioning in the disruptive group than in the comparison sample, so these factors could not explain the social communication deficits. Our study did not screen for childhood affective disorders; however, previous research has failed to find differences in pragmatic competence between typically developing children and those with a clinical diagnosis of moderate to severe depression or generalised anxiety. ${ }^{1}$

Other ways of considering the issue of the representativeness of our sample of disruptive children are as follows. The number of children meeting the overall criterion of 'disruptiveness' was 290 , of whom 26 , or $9 \%$ of the total, were intensively studied. Although every effort was made to avoid bias, could our estimate of autism-spectrum disorder traits $(9 / 26$ or $35 \%)$ have been excessively high? Assuming no bias, among all 290 disruptive children there would have been 100 with autism-spectrum disorder. The total school sample comprised 5091 children, giving an estimated autism-spectrum disorder prevalence of $1.96 \%$. Age ranges surveyed overlap with a recent UK school-based population study of 3342 pupils in Cambridgeshire, which estimated the prevalence of autism-spectrum conditions to be $1.57 \%,{ }^{36}$ taking into account formerly unrecognised cases. Our figure is therefore a little high, which may reflect bias or may reflect the nature of the children in this borough. It also assumes all children with autismspectrum disorder in the age range studied are subsumed within the 'disruptive' category. Clearly, it would be useful to know what proportion of children with autism-spectrum disorder are disruptive. Fortunately, we have access to data on disruptiveness in a more representative population sample. We have recently evaluated school adjustment in relation to social communication impairment in the Avon Longitudinal Study of Parents and Children (ALSPAC). ${ }^{37}$ Among children meeting screening criteria for a possible autism-spectrum disorder, ${ }^{38}$ for whom teacher-rated information was available (284/6233), 67 (23.6\%) were considered disruptive. Conversely, of those considered to have 'quite a lot' or 'a great deal' of disruptive behaviour at school, for whom autismspectrum disorder screening data were available, 50 of $143(35 \%)$ scored within the range for a possible autism-spectrum disorder. This latter figure is identical to the finding in our Hackney study. Only 10 out of $50(20 \%)$ of those 'screen-positive' children had a clinically diagnosed autism-spectrum disorder, ${ }^{39}$ but the ALSPAC population prevalence of $0.51 \%$ is almost certainly an underestimate. We conclude that although there may have been a degree of bias in the selection of children seen for assessment in Hackney schools, this is unlikely to have led to any serious overestimate of the prevalence of autism-spectrum disorder symptoms in persistently disruptive pupils.

\section{Clinical implications}

We suggest increased attention needs to be paid to the possibility that children presenting with conduct problems have covert neurodevelopmental disorders, as proposed by Moffitt et al. ${ }^{4}$ The presence of social communication deficits should be considered as a potential contributory factor to persistently disruptive behaviour in children of primary-school age. We suggest interventions for disruptive behaviour are unlikely to be effective if associated social communication deficits are not appreciated. ${ }^{40}$ There is a need for greater collaboration between psychiatry, educational psychology and child mental health services to meet the needs of this challenging group. Our findings underscore the importance of effective screening for social communication problems in educational, clinical, and research settings. ${ }^{30}$

\section{R. Donno, DClinPsy, Psychosocial and Family Services, Great Ormond Street Hospital, R. Donno, DClinPsy, Psychosocial and Family Services, Great Ormond Street Hospita,
London; G. Parker, DClinPsy, PhD, Rehabilitation and Health Psychology Services, Mile End Hospital, London; J. Gilmour, MD, FRCPsych, Subdepartment of Clinical
Mind Health Psychology, University College London; D. H. Skuse, Behavioural and Brain Sciences Unit, Institute of Child Health, University College London, UK}

Correspondence: Professor David Skuse, Behavioural and Brain Sciences Unit, Institute of Child Health, University College London WC1N 1EH, UK. Email: dskuse@ich.ucl.ac.uk

First received 4 Nov 2008, final revision 23 Sep 2009, accepted 21 Dec 2009

\section{Acknowledgements}

We dedicate this paper to our much loved and respected friend and colleague Dr Rose Donno, who sadly passed away on 2 January 2010. She will be forever missed by those who loved her, and by those whose lives she touched through her work.

We are indebted to the families and teachers who generously gave their time, without which this study would not have been possible.

\section{References}

1 Gilmour J, Hill B, Place M, Skuse DH. Social communication deficits in conduct disorder: a clinical and community study. J Child Psychol Psychiatry 2004; 45: 967-78.

2 Rutter M. Crucial paths from risk indicator to causal mechanism. In Causes of Conduct Disorder and Juvenile Delinquency (eds B Lahey, T Moffitt, A Caspi): 51-4. Guilford, 2004.

3 Bishop DVM, Baird G. Parent and teacher reports of pragmatic aspects of communications: use of the Children's Communication Checklist in a clinical setting. Dev Med Child Neurol 2001; 43: 809-18.

4 Moffitt TE, Caspi A, Rutter M, Silva PA. Sex Differences in Antisocial Behavior: Conduct Disorder, Delinquency and Violence in the Dunedin Longitudinal Study: 238-9. Cambridge University Press, 2001.

5 De Bruin E, Ferdinand RF, Meester S, de Nijs PFA, Verheij F. High rates of psychiatric comorbidity in PDD-NOS. J Autism Dev Disord 2007; 37: 877-86.

6 Barnard J, Prior A, Potter D. Inclusion and Autism: Is It Working? National Autistic Society, 2000

7 Liss M, Fein D, Allen D, Feinstein C, Morris R, Waterhouse L, et al. Executive functioning in high-functioning children with autism. J Child Psychol Psychiatry 2001; 42: 261-70.

8 Buitelaar J, van der Wees M, Swaab-Barneveld $\mathrm{H}$, van der Gaag R. Verbal memory and performance IQ predict theory of mind and emotion recognition ability in children with autistic spectrum disorders and in psychiatric control children. J Child Psychol Psychiatry 1999; 40: 869-81.

9 Dawson G, Carver L, Meltzoff A, Panagiotides H, McPartland J, Webb S. Neural correlates of face and object recognition in young children with autism spectrum disorder, developmental delay, and typical development. Child Dev 2002; 73: 700-17.

10 Campbell R, Lawrence K, Mandy W, Mitra C, Jeyakuma L, Skuse D. Meaning in motions and faces: developmental associations between the processing of intention from geometrical animations and gaze detection accuracy. Dev Psychopathol 2006; 18: 99-118.

11 Baron-Cohen S, Leslie AM, Frith U. Does the autistic child have a 'theory of mind'? Cognition 1985; 21: 37-46. 
12 Bolton P, Gillie C. Faith Schools: Admissions and Performance. Standard Note SN/SG/4405. Social Policy Section, House of Commons Library, 2009.

13 Office for Standards in Education. Section 10 Inspection Evidence for Deprived Urban Schools. Ofsted, 2009 (http://www.docstoc.com/search/ Urban-Schools).

14 Department for Education and Skills. Permanent and Fixed Term Exclusions from Schools and Exclusion Appeals in England 2003/04. DfES, 2005.

15 Bishop DVM. Uncommon Understanding: Development and Disorders of Language Comprehension in Children. Psychology Press, 1998.

16 Cohen J. A power primer. Psychol Bull 1992; 112: 155-9.

17 Skuse D, Warrington R, Bishop D, Chowdhury U, Lau J, Mandy W, et al The Developmental, Dimensional and Diagnostic Interview (3di): a novel computerized assessment for autism spectrum disorders. J Am Acad Child Adolesc Psychiatry 2004; 43: 548-58.

18 Lord C, Rutter M, Le Couteur A. Autism Diagnostic Interview Revised: a revised version of a diagnostic interview for caregivers of individuals with possible pervasive developmental disorders. J Autism Dev Disord 1994; 24: 659-85.

19 American Psychiatric Association. Diagnostic and Statistical Manual of Mental Disorders (4th edn, text revision) (DSM-IV-TR). APA, 2000.

20 World Health Organization. The ICD-10 Classification of Mental and Behavioural Disorders: Multi-axial Classification of Child and Adolescent Psychiatric Disorders. WHO, 1996.

21 Wechsler, D. Wechsler Abbreviated Scale of Intelligence. Psychological Corporation, 1999

22 Manly T, Robertson IH, Anderson V, Nimmo-Smith I. The Test of Everyday Attention for Children (TEA-Ch). Thames Valley Test Company, 1998.

23 Skuse D, Lawrence K, Tang J. Measuring social-cognitive functions in children with somatotropic axis dysfunction. Horm Res 2005; 64: 73-82.

24 Ekman P, Friesen W. Pictures of Facial Affect. Consulting Psychologists Press, 1976.

25 Warrington EK. Recognition Memory Test. nferNelson, 1984.

26 Castelli F, Frith C, Happé F, Frith U. Autism, Asperger syndrome and brain mechanisms for the attribution of mental states to animated shapes. Brain 2002; 125: 1839-49.

27 Salter G, Seigal A, Claxton M, Lawrence K, Skuse DH. Can autistic children read the mind of an animated triangle? Autism 2008; 4: 349-71.
28 Baron-Cohen S, Wheelwright S, Hill J, Raste Y, Plumb I. The 'Reading the Mind in the Eyes' Test revised version: a study with normal adults, and adults with Asperger syndrome or high-functioning autism. J Child Psychol Psychiatry 2001; 42: 241-51.

$29 \mathrm{Kim} \mathrm{OH}$, Kaiser AP. Language characteristics of children with attention deficit hyperactivity disorder. Communication Dis Quart 2000; 21: 154-65.

30 Towbin K, Pradella A, Gorrindo T, Pine DS, Leibenluft E. Autistic spectrum traits in children with mood and anxiety disorders. J Child Adolesc Psychopathol 2005; 15: 452-64.

31 Szatmari P, Georgiades S, Bryson S, Zwaignenbaum L, Roberts W, Mahoney $W$, et al. Investigating the structure of the restricted, repetitive behaviours and interests domain of autism. J Child Psychol Psychiatry 2006; 47: 582-90.

32 Mandy WP, Skuse DH. Research review: what is the association between the social-communication element of autism and repetitive interests, behaviours and activities? J Child Psychol Psychiatry 2008; 49: 795-808.

33 Brent $E$, Rios $P$, Happé $F$, Charman T. Performance of children with autism spectrum disorder on advanced theory of mind tasks. Autism 2004; 8 283-99.

34 Noble KG, Norman MF, Farah MJ. Neurocognitive correlates of socioeconomic status in kindergarten children. Dev Science 2005; 8: 74-87.

35 Plomin P, Price TS, Eley TC, Dale PS, Stevenson J. Associations between behavior problems and verbal and nonverbal abilities and disabilities in early childhood. J Child Psychol Psychiatry 2002; 43: 619-33.

36 Baron-Cohen S, Scott FJ, Allison C, Williams J, Bolton P, Matthews FE, et al. Prevalence of autism-spectrum conditions: UK school-based population study. Br J Psychiatry 2009; 194: 500-9.

37 Skuse D, Mandy W, Steer C, Miller L, Goodman R, Lawrence K, et al. Social communication competence and functional adaptation in a general population of children: preliminary evidence for sex-by-verbal IQ differential risk. J Am Acad Child Adolesc Psychiatry 2009; 48: 128-37.

38 Skuse DH, Mandy WPL, Scourfield J. Measuring autistic traits: heritability, reliability and validity of the Social and Communication Disorders Checklist. Br J Psychiatry 2005; 187: 568-72.

39 Williams E, Thomas K, Sidebotham $\mathrm{H}$, Emond A. Prevalence and characteristics of autistic spectrum disorders in the ALSPAC cohort. Dev Med Child Neurol 2008; 50: 672-7.

40 Fishbein DH, Hyde C, Eldreth D, Paschall MJ, Hubal R, Das A, et al. Neurocognitive skills moderate urban males responses to preventive intervention materials. Drug Alcohol Depend 2006; 82: 47-60. 